\title{
Inaplicabilidad de la Probation Como Respuesta Penal Frente a la Violencia Contra la Mujer ${ }^{1}$
}

Fernando M. Rodrigo ${ }^{2}$

Jessica R. Gimenez ${ }^{3}$

\section{RESUMEN}

La violencia contra las mujeres se encuentra presente en todas las sociedades del mundo, constituyéndose en una de las manifestaciones más brutales de desigualdad entre los géneros. El Derecho penal es un instrumento cualificado de protección de bienes jurídicos especialmente importantes. Sentado esto, parece obligado tener en cuenta la posibilidad de que su expansión obedezca, al menos en parte, ya a la aparición de nuevos bienes jurídicos -de nuevos intereses o de nuevas valoraciones de intereses preexistentes, ya al aumento de valor experimentado por algunos de los que existían con anterioridad, que podría legitimar su protección a través del Derecho Penal. Un objetivo primordial para eliminar los patrones socioculturales androcéntricos es la incorporación de la perspectiva de género en

\footnotetext{
1 Data de recebimento: 24/11/2017. Data de aceite: 19/01/2018.

2 Fiscal Adjunto de la Unidad Fiscal Investigación y Juicio $\mathrm{N}^{\circ} 1$-sede ciudad de Rosario- del Ministerio Público de la Acusación de la Provincia de Santa Fe, República Argentina - Presidente de la Asociación de Fiscales del Ministerio Público de la Acusación de la Provincia de Santa Fe, República Argentina Magister en Derecho Procesal (Facultad de Derecho de la Universidad Nacional de Rosario -U.N.R.-, República Argentina) - Abogado (Facultad de Derecho de la Universidad Nacional de Rosario -U.N.R.República Argentina); Mediador Penal (Ministerio de Justicia y Derechos Humanos de la Provincia de Santa Fe, República Argentina); Docente de la Facultad de Derecho de la Universidad Nacional de Rosario, República Argentina (cátedras de Introducción al Derecho y Derecho Procesal Penal, y ex Docente de Derecho Penal I -Parte General-); Profesor del Instituto de Seguridad Pública (I.Se.P.) -ex Escuela de Cadetes de Policías- de la Provincia de Santa Fe, República Argentina. Miembro de la Asociación Internacional de Derecho Penal (AIDP) y de International Association of Prosecutors (IAP). E-mail: fernandorodrigo1@gmail.com

3 Pasante del Ministerio Público de la Acusación de la Provincia de Santa Fe -sede ciudad de Rosario-, República Argentina; Abogada de la Facultad de Derecho de la Universidad Nacional de Rosario -U.N.R.-, República Argentina.
} 
la prestación de justicia, desde el ámbito de las relaciones laborales hasta en el dictado de resoluciones y sentencias, pasando por el trato de las víctimas y el tratamiento de las causas. La Convención Interamericana para Prevenir, Sancionar y Erradicar la Violencia contra la Mujer, Convención de Belém do Pará, prevé la obligación de los Estados de adoptar, por todos los medios apropiados y sin dilaciones, políticas orientadas a prevenir, sancionar y erradicar dicha violencia, a lo que se agrega la necesidad de establecer procedimientos legales justos y eficaces para la mujer que haya sido sometida a violencia, que incluyan, entre otros, medidas de protección, un juicio oportuno y el acceso efectivo a tales procedimientos.

Palabras clave: Violencia contra la mujer. Derecho Penal. Probation.

\section{INTRODUCCIÓN}

La violencia contra las mujeres se encuentra presente en todas las sociedades del mundo, no hace distinciones de culturas, clases sociales o etnias, constituyéndose en una de las manifestaciones más brutales de desigualdad entre los géneros. Esta clase de violencia se manifiesta de diferentes maneras y en múltiples espacios, cristalizándose en un problema cultural complejo ${ }^{4}$.

Para muchísimas mujeres, lamentablemente, la violencia es omnipresente y un firme elemento integrante de sus vidas y experiencias cotidianas, donde no están seguras de ningún modo. La violencia contra las mujeres no es una materia que pertenezca a un ámbito o rama del derecho, sino que, por el contrario, es parte de todos los ámbitos jurídicos, donde se transgreden diversos derechos, verbigracia, su integridad física y psíquica y su libertad (Derecho penal) o su

4 RODRIGO, Fernando M., "Estrategias de defensas para mujeres que responden a las agresiones de sus maltratadores", en Sup. Penal2013 (septiembre), 3 - L.L. 2013-E, 544. 
estado civil o relaciones de familia (Derecho civil).

Durante muchos el sistema de justicia penal consideraba la violencia de género como un problema menor que escapaba a su jurisdicción. Recientemente se ha comenzado a movilizar recursos para poner freno a este problema, la convergencia de los intereses de grupos defensores de los derechos de la mujer y de otros actores sociales y políticos "ha conducido a una serie de respuestas tendientes a fortalecer el etiquetamiento como criminal de la violencia doméstica y el maltrato" ${ }^{\prime \prime}$.

En el mundo, diariamente, se violan los derechos humanos de miles de mujeres, que sufren la violencia en todas sus facetas: la física, sexual y psicológica. Ello acontece en todos los ámbitos: en el familiar (malos tratos, abuso sexual de las niñas, violación a manos del marido), en el político-religioso (mutilación genital femenina, exclusión social) y socioeconómico (explotación laboral y sexual) ${ }^{6}$.

El Estado de Derecho posee mecanismos específicos para que las personas garanticen sus derechos en casos extremos, no los promueve, los tolera. Con una visión más amplia estas situaciones justifican y comprenden aristas no solo legales sino también psicológicas, antropológicas, sociales y políticas, que consagren un Derecho Penal válido, eficaz y justo7 , el "problema" es en qué medida el tratamiento penal persigue las conductas denunciadas y protege a las mujeres que sufren violencias.

\section{NUEVOS RETOS DEL SISTEMA PUNITIVO Y ABORDAJE DEL ESTADO ANTE LA VIOLENCIA DE GÉNERO}

El Derecho intenta aprisionar el tiempo, insertándolo dentro de un

5 MEDINA, Juan J., "Violencia contra la mujer en la pareja", (Valencia, Tirant lo Blanch, 2002), pág. 377. 6 Comas d'Argemir, Montserrat, "La lucha internacional contra la violencia de género", diario El País, 25 de noviembre de 2006, en

http://elpais.com/diario/2006/11/25/opinion/1164409213_850215.html (consultada 15/12/2014) 7 VITALE, Gustavo L., "Estado constitucional de Derecho y Derecho Penal”, en AA.VV., "Teorías actuales en el Derecho Penal", (Buenos Aires, Ad-Hoc, 1998), págs. 74/5. 
orden formal que establece los criterios de las periodicidades. Niega al tiempo su papel de patrón de los ritmos y de las medidas y trata de obligarlo a regirse por las rutinas y secuencias del orden jurídico.

El tiempo nunca ha resistido, menos aún en nuestra época, los encasillamientos del Derecho, por lo que se evade por los grietas del sistema envolviendo al sistema mismo, modelándolo y adaptándolo a una lógica diferente.

El derecho punitivo tiene por misión la protección de la convivencia humana en la comunidad ${ }^{8}$, el Derecho Penal es la parte del control social, que resulta institucionalizado en forma punitiva y con discurso punitivo, el fundamento del mismo radica en su necesidad

(...) para garantizar la protección de la sociedad a través de la prevención general y especial de delitos: protección de los bienes jurídicos más preciados contra los ataques a los mismos más intolerables ... actualmente y para un futuro previsible parece indiscutible la necesidad de recurrir al Derecho penal para la protección de la convivencia social soportable?.

En este contexto de marginalización y contraintegración, al Derecho Penal le comprende la aceptación y asunción de la marginalidad y situaciones especiales de violencia, otorgando soluciones especiales y particulares para la comisión de los ilícitos en tales circunstancias.

En el Derecho Penal de la postmodernidad ${ }^{10}$, el legislador, como el juez, y los demás operadores jurídicos, deben actuar en sectores antes no comprendidos o alcanzados por las normas penales.

El Derecho penal es un instrumento cualificado de protección de bienes jurídicos especialmente importantes. Sentado esto, parece obligado tener en cuenta la posibilidad de que su expansión obede-

8 JESCHECK, Hans - Heinrich, "Tratado de Derecho Penal, Parte General", 4º Edición, Traducción de José Luis Manzanares Samaniego, (Granada, España, Editorial Comares - Granada, 1993), pág. 1. 9 LUZON PEÑA, Diego Manuel, "Curso de Derecho Penal, Parte general", tomo I, $1^{\circ}$ edición, $1^{\circ}$ reimpresión, (Madrid, Editorial Universitas S.A., 1999), pág. 79.

10 HASSEMER, Winfried, "Persona, mundo y responsabilidad", trad. de Francisco Muñoz Conde y María del Mar Díaz Pita, (Colombia, Temis, 1999), págs. 15 y ss. 
zca, al menos en parte, ya a la aparición de nuevos bienes jurídicos -de nuevos intereses o de nuevas valoraciones de intereses preexistentes-, ya al aumento de valor experimentado por algunos de los que existían con anterioridad, que podría legitimar su protección a través del Derecho Penal ${ }^{11}$.

La intervención penal por sí sola resulta ineficaz para resolver el conflicto y tiende a revictimizar a la mujer que llega al sistema judicial en demanda de ayuda, ya que sus reglas exigen certeza absoluta para la condena y requiera de un prolongado período de tiempo entre la denuncia y la sentencia acusatoria, absolutoria o de suspensión de juicio a prueba, lo que se puede considerar como inadecuado e ineficaz a los criterios de peligrosidad, urgencia y riesgo de cada caso, en función de la protección de la mujer victima de la violencia de género.

Al respecto sabemos que el Derecho Penal tiene por sujeto principal al imputado y no a la mujer víctima, aunque en el sistema de suspensión del proceso penal a prueba - para aquellos que consideran posible su aplicación a los casos de violencia de género- la misma es escuchada a los fines de aceptar o no la reparación del daño ofrecida por el imputado.

En nuestros días existen normas que protegen y garantizan innumerables derechos a la mujer ${ }^{12}$, no obstante se halla un gran déficit funcional e institucional para abordar el fenómeno de los malos tratos a las mujeres, tal vez, ello se encuentre dado en la incomprensión de que la violencia de género presenta caracteres materiales, sociales y

\footnotetext{
11 En tal sentido puede v. SILVA SANCHEZ, Jesús María, "La expansión del Derecho Penal", $2^{\circ}$ edición, (Madrid, Civitas, 2001), págs. 25 y ss. También c. AA.VV., "Crítica y Justificación del Derecho Penal en el cambio de siglo", coords.: Luis Arroyo Zapatero y otros, (Cuenca, Ediciones de la Universidad de Castilla-La Mancha, 2003).

12 En nuestro país además de las normas generales existen normas especiales que protegen a la mujer, las cuales son las siguientes: Ley № 26.485 de Protección Integral para prevenir, sancionar y erradicar la violencia contra las mujeres en los ámbitos en que desarrollen sus relaciones interpersonales. (11/03/2009); Reglamentación de la Ley 26.485: Decreto 101/2010; Ley № 26.472 de Ejecución de la Pena Privativa de la Libertad, que contempla el supuesto de Prisión Domiciliaria para madres con hijos menores de cinco (5) años, para la mujer embarazada, entre otros; Ley № 26.364 y Ley № 26.842 de Prevención y Sanción de la Trata de Personas y Asistencia a sus Víctimas; Ley N 26.171 de aprobación de Protocolo Facultativo de convención sobre Eliminación de todas las Formas de Discriminación contra la Mujer; Ley N 25.673 de creación de Programa Nacional de Salud Sexual y Procreación Responsable Ley $N^{\circ} 24.012$ de Cupo Femenino (en Santa Fe Ley $N^{\circ} 10.082$ ); entre otras.
} 
psicológicos muy diferentes a las demás violencias interpersonales.

La violencia contra la mujer, en sus diferentes formas ${ }^{13}$, se ha ido delimitando como una de las áreas delictivas más complejas y dañinas en las sociedades modernas, las múltiples actuaciones de tratamiento punitivo, no alcanzan a responder a los resistentes comportamientos violentos, lo cual se demuestra en el crecimiento de los casos violentos como en la reincidencia de los mismos.

La acción violenta contra la mujer está orientada a someterla mediando una combinación de agresiones físicas y psíquicas que integran un abanico amplio de infracciones penales constitutivas por ejemplo de lesiones, abuso sexual, privaciones de su libertad, malos tratos, amenazas, desobediencia a órdenes judiciales o coacciones. El agresor acomete contra la mujer procurando producir miedo a seguir sufriendo daños sobre sí misma, sobre sus hijos u otro miembro o persona sobre la que el agresor ejerza algún acto de poder ${ }^{14}$.

Los operadores del Derecho Penal deben comenzar a considerar estas situaciones que ocurren sostenida y repetidamente en nuestra sociedad, una visión moderna del Derecho Penal debe instituir homogeneidad y aceptación de la realidad social, no debe endurecerse ante estas situaciones, sino que debe captarlas y valorarlas, especialmente cuando la mujer responde y enfrenta los maltratos que sufre constantemente, lo contrario significaría un miope entendimiento.

Un objetivo primordial para eliminar los patrones socioculturales androcéntricos ${ }^{15}$ es la incorporación de la perspectiva de género en la prestación de justicia, desde el ámbito de las relaciones labora-

\footnotetext{
13 Las mujeres maltratadas sufren diferentes situaciones de violencia entre las que pueden nombrarse la violencia psicológica, las agresiones físicas, la violencia sexual, la presión económica, el acoso por intrusión (stalking) hasta llegar al homicidio de la mujer.

14 RODRIGO, op. cit., L.L. 2013-E, 544.

$15 \mathrm{El}$ androcentrismo es la organización de las estructuras económicas, socioculturales y políticas a partir de la imagen del hombre; un enfoque que fundamenta las experiencias humanas, el protagonismo de la historia y el desarrollo desde una perspectiva masculina. De esta forma, este concepto alude a una cosmovisión masculina del conjunto de relaciones sociales. También revela la condición de las mujeres, como puede ser la falta de oportunidades en la toma de decisiones y en aspectos laborales. En tal sentido v. Honorable Cámara de Diputados de la Provincia de Buenos Aires, Diccionario de Género. Incluye la Ley Provincial 12.569, http://www.hcdiputados-ba.gov.ar/weboaci/files/diccionario. pdf (consultada el 08/01/2015).
} 
les hasta en el dictado de resoluciones y sentencias, pasando por el trato de las víctimas y el tratamiento de las causas. La falta de incorporación de la perspectiva de género producirá la denominada "violencia institucional", que es receptada por nuestra legislación a partir de los tratados internacionales y que se encuentra en el art. 6 inc. b) de la Ley $\mathrm{N}^{\circ} 26.485$.

Esta necesidad es señalada por Facio al plantear que:

Pensemos si no en los efectos que tendría en la concepción del sujeto paradigmático del derecho: el buen padre de familia, si todas las normas fueran aplicadas desde una perspectiva de género. Pasaría que poco a poco el derecho judicial habría transformado al sujeto paradigmático del derecho en un sujeto más inclusivo de las necesidades y diferencias entre los seres humanos lo que a su vez transformaría el contenido de las normas del derecho judicial (...) tener jueces y juezas sensibles al género interpretando y aplicando las leyes neutras desde una perspectiva de género [haría] que el fenómeno jurídico fuera generalmente justo ${ }^{16}$.

El Estado tiene responsabilidad de actuar con diligencia, esto ha sido resaltado por la Comisión Interamericana de Derechos Humanos al expresar que la "inefectividad judicial general y discriminatoria crea el ambiente que facilita la violencia doméstica, al no existir evidencias socialmente percibidas de la voluntad y efectividad del Estado como representante de la sociedad, para sancionar esos actos"17.

Resulta de lo expuesto, primero la necesidad de que el Estado visualice y asuma medidas protectoras y respuestas adecuadas ante la violencia de género, para que, en segundo lugar, el derecho punitivo ante el proceso y dinámica de la violencia de género perfectamente identificada en el "ciclo de violencia", brinde una intervención conveniente de medidas preventivas como también al tratamiento de los sujetos, la aplicación y determinación de la pena o en su caso la

16 FACIO, Alda, 'Con los lentes del género se ve otra justicia', en AA.VV., 'Otras miradas de la justicia. El otro derecho', número 28, "Bogotá, ILSA -Instituto Latinoamericano de Servicios Legales Alternativos, 2002), págs. 95/6.

17 Comisión IDH, Informe № 54/01, 16/04/2001, caso María Da Penha Maia Fernandes. 
aplicación o no de institutos como la suspensión del juicio a prueba.

\section{LA SUSPENSIÓN DEL JUICIO A PRUEBA: SUS PRINCIPALES CARACTERÍSTICAS DE LA PROBATION:}

La ley $24.316^{18}$, introdujo, al Código Penal, el instituto de la suspensión del juicio a prueba -conocido como probation- en los arts. 76bis, ter y quater, mediante el cual el justiciable puede solicitar la suspensión del juicio ${ }^{19}$, debiendo para ello ofrecer una reparación razonable a la víctima y cumplir con las reglas de conducta que le imponga el tribunal.

La legislación de nuestro país propone hacer suyos los principios rectores que surgen del derecho internacional y de la normativa constitucional, de tal modo se plasma a nivel nacional uno de los objetivos fundamentales de las Reglas mínimas de las Naciones Unidas sobre las medidas no privativas de la libertad (Reglas de Tokio) ${ }^{20}$.

A grandes rasgos, lo que se advierte es que el sentido de la previsión del art. 76 bis del Código Penal, esto es la voluntad del legislador, en su correcta lectura conforme las directrices de la Corte Suprema de Justicia de la Nación (C.S.J.N.), con claras intenciones de descongestionar el sistema judicial y eludir la estigmatización de las condenas para los delitos de bagatela o de nimia afectación al bien jurídico tutelado - casos del primer y segundo párrafo de la normativa-, o de media relevancia — casos del cuarto párrafo-, es que para los casos leves la probation corresponde por derecho,

\footnotetext{
18 Adla, LIV-E, 1400

19 ERBETTA, Daniel, FRANCESCHETTI, Gustavo y ORSO, Tomás, 'Código Procesal Penal de la Provincia de Santa Fe. Texto vigente según leyes 6740, 12734 y 12912, Análisis y comentario a la Ley de implementación Progresiva y artículos de la ley 12734 que entran en vigencia', (Santa Fe, Rubinzal Culzoni, 2009), pág. 120.

20 'Los Estados miembros introducirán medidas no privativas de la libertad en sus respectivos ordenamientos jurídicos para proporcionar otras opciones y de esta manera reducir la aplicación de las penas de prisión y racionalizar las políticas de justicia penal, teniendo en cuenta el respeto de los Derechos Humanos, las exigencias de la Justicia Social y las necesidades de rehabilitación del delincuente' (Regla de Tokio, regla 1.5). Adoptadas por la Asamblea General en su resolución 45/110, de 14 de diciembre de 1990.
} 
pero requiere del consentimiento Fiscal, cuyo dictamen no escapa al control de logicidad y razonabilidad, es decir per se, su opinión no es vinculante.

A partir de la entrada en vigencia de la figura de la probation, la doctrina autoral y jurisprudencial han examinado y fijado paulatinamente los perfiles de la figura, precisando el pensamiento respecto de puntos controvertidos de la norma.

En esta dirección, De Olazábal ha sostenido que:

(...) a todas luces se evidencia que los elementos configurantes del eventual delito atribuido en nada se desmerecen por la aparición de la suspensión del juicio a prueba. La actuación de éste se circunscribe exclusivamente a la punibilidad, sobre la que opera bloqueándola (provisoria o definitivamente en caso de que se cumplan las condiciones fijadas). A diferencia de la condena condicional, la probation no configura una pena, puesto que no se llega al pronunciamiento de tal, ni, por las mismas razones -entre otras, obviamente- una medida de seguridad (... ${ }^{21}$

Por su parte las doctrina judicial ha señalado que:

(...) no implica una condena en sentido específico, sino que es la renuncia a la potestad punitiva del Estado; no es una sentencia, es una medida revocable que abre un status procesal específico, que suspende el procedimiento sancionatorio común, otorgando una oportunidad de reforma y al mismo tiempo una posibilidad de condena en caso de incumplimiento de las condiciones a que la somete el juez. La resolución que deniega la suspensión del juicio a prueba es revisable para la defensa durante el plenario pudiendo ésta plantear, durante el debate oral, el recurso de reposición contra un rechazo de la suspensión pedida y, en su caso, hacer formal protesta de recurrir en casación para la hipótesis de condena. Las resoluciones que conceden o deniegan la suspensión del juicio a prueba no encuadran dentro de los supuestos del art. $457 \mathrm{CPr} . \mathrm{Cr} \ldots{ }^{22}$

21 DE OLAZABAL, Julio, "Suspensión del proceso a prueba", (Buenos Aires, Astrea, 1994), págs. 19/20. 22 CNCasación Penal, sala II, Capital Federal, 24/06/1997, in re "Enciso, Lorenzo y otro", JUBA Penal 10468, J.A. 1999-II, 547 
Teniendo por finalidad: “(a) descomprimir el sistema penal, (b) brindar mayor protección a la víctima, (c) buscar la integración social de los imputados, (d) evitar un antecedente condenatorio para el imputado y el menor costo económico, por cuanto el proceso, en principio, se finaliza antes"23.

Más allá de las razones de política carcelaria que parte de los juristas ${ }^{24}$ hacen mención para justificar la aplicación del instituto, se verifica que su empleo, en un caso concreto, paraliza el trámite normal del proceso penal impidiendo a la propia jurisdicción el dictado de la sentencia. De allí que piense De Olazábal, haciendo exégesis de la norma, que se trata de un modo de extinción condicionado al cumplimiento de las pautas fijadas en la ley ${ }^{25}$. Esta suspensión del proceso penal, evidentemente, obsta a la merituación cierta y definitiva de la relación de causalidad entre el hecho y el daño acaecido, además de no evaluarse la reprochabilidad social de la conducta del imputado a la luz de norma penal, circunstancias que interesan a a los hechos donde son víctimas las mujeres en manos de los hombres que avasallan no sólo sus derechos sino también su integridad física como psíquica, dejando muchas veces huellas imborrables en dichas mujeres.

\section{DICTAMEN FISCAL SOBRE LA PROCEDENCIA DE LA SUSPENSIÓN DE JUICIO A PRUEBA}

El cuarto párrafo del art. 76 bis menciona que debe mediar consentimiento del fiscal para que el tribunal pueda suspender el juicio a prueba.

La exigencia del dictamen fiscal favorable para la procedencia de la probation (art. 76 bis - $4^{\circ}$. párr.- del Código Penal) es conse-

23 BACLINI, Jorge C., "Código Procesal Penal de la Provincia de Santa Fe. Ley No 12.734", Tomo I - arts. 1 a 125-, (Rosario, Juris, 2010), pág. 133.

24 Puede verse por ejemplo: FREELAND LOPEZ LECUBE, Alejandro y TAMINI, Adolfo, “¿Probation a la manera americana, a la europea o qué?", J.A. 1994-IV, 859.

25 DE OLAZABAL, ob. cit., pág. 21. 
cuencia de la vinculación de este instituto con el principio procesal de oportunidad. Ello así, puesto que los criterios de política criminal que hacen a la oportunidad de mantener la persecución penal, deben quedar en manos exclusivas del órgano promotor de la acción y no de quien ejerce la jurisdicción, y el tribunal no está habilitado para examinar la razonabilidad del pedido o de la oposición.

Para que el dictamen fiscal negativo vincule al juez en el trámite para la concesión de la suspensión del juicio a prueba, el mismo debe reunir determinadas condiciones, ello es así, pues una denegatoria carente de debida fundamentación configura un ejercicio arbitrario de la aludida potestad por parte del Ministerio Público, el cual autoriza a prescindir del mentado requisito legal.

La Cámara Nacional de Casación Penal resolvió en el plenario "Kosuta" que la oposición fiscal es vinculante para el otorgamiento del beneficio, siendo ello seguido en el ámbito provincial por los diferentes tribunales que la componen, señalándose además que no constituye un mero dictamen sobre la procedencia de la suspensión del juicio a prueba y que, salvo supuestos excepcionales de arbitrariedad, la oposición fundada de quien es titular de la acción pública, resulta vinculante para el juzgador.

En un caso se ha expuesto que el derecho a peticionar, por parte del imputado, la probation

(...)no implica una aceptación automática ni obligatoria, sino que ello permite la opinión y participación de otros actores del proceso penal, tal como el titular de la acción, el Ministerio Fiscal y eventualmente, el de la víctima; en tanto también debe tenerse presente las características del hecho, la entidad o gravedad que el mismo pudiera haber tenido, las circunstancias personales de cada acusado, sujetos únicos e irrepetibles con su impronta, como también razones de política criminal en lo que hace a la protección de los bienes jurídicos, y la necesidad de sancionar las infracciones, en pos del cumplimiento del mandato constitucional indicado en el Preámbulo Constitucional de "afianzar la justicia" y los derechos de las víctimas y/o damnificados llevando a que el Estado, a través del Ministerio Público 
Fiscal tenga el derecho a oponerse, resaltando una vez más, que es ese Ministerio el que es titular de la acción, en la tarea de instar y ejercer la misma. ${ }^{26}$

El Procurador Fiscal ante la Corte Suprema de Justicia de la Nación, sostuvo en la causa "Pusterla", que

\begin{abstract}
El consentimiento del fiscal constituye un requisito para la suspensión de la realización del juicio, por lo que si el juez considera que su dictamen carece de adecuada fundamentación, debe anularlo y permitirle exponer nuevamente su posición (...) Esto es así ya que el órgano jurisdiccional no cuenta con la facultad de promover ni de suspender el ejercicio de la acción penal, el que, de acuerdo con el artículo 120 de la Constitución Nacional, se encuentra a cargo del Ministerio Público Fiscal. Por lo tanto, cabe concluir que el consentimiento del fiscal es indispensable para la aplicación del instituto en cuestión, desde que provoca la suspensión de aquella potestad y puede además llevar a la extinción de la acción ${ }^{27}$.
\end{abstract}

Esta exégesis ha sido sustentada en que la suspensión del juicio a prueba constituye un modo de extinción de la acción penal gestado mediante el acuerdo de voluntades entre ofensor y ofendido, realizado con "aquiescencia del titular de la acción que así resigna su ejercicio en aras de la resolución del conflicto"28, por lo que no lográndose ese acuerdo, la voluntad del Estado -a través del Ministerio Público Fiscal- es la que debe primar en una solución que pone en juego la posibilidad de disponer de la acción penal.

\title{
5 VIOLENCIA DE GÉNERO Y
}

26 Colegio de Cámara de Apelaciones en lo Penal de Rosario, Juez de Cámara Otto Crippa García, Auto N ${ }^{\circ} 724,02 / 12 / 2014$, en autos "SANCHEZ, Cristian Daniel s/Suspensión de Procedimiento a Prueba Apelación". En el mismo sentido Cámara de Apelación de Rosario, Sala III, en autos "Gonzalez Sergio", Auto N² 278 del 19.08.2011; “Cañete Luis”, Auto N²81 del 11.08.2010.

27 Dictamen del Procurador General de la Nación Eduardo Casal, 22/12/2011, en autos “Pusterla, Pablo José y otros S/ causa n¹5.203", Expediente P.772.XLVII,

http://servicios.csjn.gov.ar/confal/ConsultaCompletaFallos.do?method=verAnalisisDocumental\& id=695025

28 AA.VV., "Código Penal de la Nación. Comentado y Anotado", ob. cit, pág. 1112. 


\section{SUSPENSIÓN DE JUICIO A PRUEBA}

Uno de los temas más discutidos en el ámbito doctrinario y jurisprudencial de los últimos tiempos, es todo lo relacionado a lo que se ha llamado violencia de género. Es que a partir de la sanción de la ley nacional 24.632 el Estado argentino aprobó la Convención Interamericana para Prevenir, Sancionar y Erradicar la Violencia contra la Mujer, Convención de Belém do Pará.

Dicho tratado presta especial atención a la violencia contra la Mujer, incluyendo en este concepto cualquier violencia, mediante acción o conducta, basada en su género, que cause muerte, daño o sufrimiento físico, sexual o psicológico a la mujer, tanto en el ámbito público como en el privado, y que tenga lugar dentro de la familia o unidad doméstica o en cualquier otra relación interpersonal, ya sea que el agresor comparta o haya compartido el mismo domicilio que la mujer, señalando que abarca, actos de violación, maltrato y abuso sexual; o que tenga lugar en la comunidad y sea perpetrada por cualquier persona y comprende, entre otros, violación, abuso sexual, tortura, trata de personas, prostitución forzada, secuestro y acoso sexual en el lugar de trabajo, así como en instituciones educativas, establecimientos de salud o cualquier otro lugar, ya sea perpetrada o tolerada por el Estado o sus agentes, dondequiera que ocurra ${ }^{29}$.

El antecedente esencial en la presente temática lo constituye el fallo "Góngora"30 dictado por nuestro máximo tribunal donde se estableció en términos generales que dentro de los objetivos establecidos por la "Convención de Belem do Pará" está el de establecer un "procedimiento, justo y eficaz para la mujer" que incluya "un juicio

\footnotetext{
29 IRIBARREN, Pablo E., "Violencia de género y suspensión de juicio a prueba", DJ 24/12/2014, 21, Cita Online: AR/DOC/3677/2014.

30 CSJN, 23/04/2013, en autos "Góngora, Gabriel A. c/14092", Fallo G 61, XLVII. La CSJN, abrió el recurso de hecho por considerarlo formalmente procedente porque se pone en tela de juicio la inteligencia de las normas de un tratado internacional (artículo 7 de la Convención Interamericana para Prevenir, Sancionar y Erradicar la Violencia contra la Mujer) y lo resuelto por el superior tribunal de la causa, esto es la Cámara Federal de Casación Penal, es contrario al derecho que el recurrente sustentó en ellas (artículo 14, inciso 3", de la ley 48).
} 
oportuno" (inc. f), y que ello impone, en el marco del compromiso asumido por el Estado Nacional al suscribir dicha Convención, la improcedencia de la adopción de alternativas distintas en los casos de violencia de género.

Que aquellas alternativas no se encuentran dentro de lo que puede considerarse "un juicio oportuno" y que el sentido del término "juicio" sólo es compatible con la etapa final del procedimiento (juicio oral), único momento en el cual puede derivar el pronunciamiento definitivo sobre la culpabilidad o la inocencia del imputado, es decir, la posibilidad de sancionar esta clase de hechos exigidos por aquella Convención, así sostuvo que:

\begin{abstract}
Corresponde revocar la decisión que anuló el auto que había rechazado la solicitud de suspensión del juicio a prueba (art. 76 bis, CPen.) en una causa en que no se ha puesto en crisis la calificación de los sucesos investigados como hechos de violencia contra la mujer, ya que el art. 7 de la Convención Interamericana para Prevenir, Sancionar y Erradicar la Violencia contra la Mujer impone considerar que en el marco de un ordenamiento jurídico que ha incorporado al referido instrumento internacional como nuestro país, la adopción de alternativas distintas a la definición del caso en la instancia del debate oral es improcedente, lo que surge de considerar que el sentido del término juicio ('un juicio oportuno' según el inc. f del artículo mencionado) resulta congruente con el significado que en los ordenamientos procesales se otorga a la etapa final del procedimiento criminal, en tanto únicamente de allí puede derivar el pronunciamiento definitivo sobre la culpabilidad o inocencia del imputado, es decir, verificarse la posibilidad de sancionar esta clase de hechos exigida por la Convención.
\end{abstract}

\title{
5.1 Posición que admite la aplicación de la probation a la violencia de género
}

Esta postura, denominada tesis amplia, entiende que realizando una exégesis de los antecedentes jurisprudenciales y la normativa aplicable, el rechazo de la aplicación del instituto no debe ser sis- 
temático en los casos de violencia de género, sino que se deben tener presentes las circunstancias específicas, teniendo siempre en consideración los derechos de la víctima respecto de las previsiones del Art. 7, Convención Interamericana para prevenir, sancionar y erradicar la violencia contra la mujer, especialmente sus incs. b), c) y f), Convención de Belem do Pará.

Agregan que la suspensión de la persecución en el universo de casos definido por el art. 76 bis del Código Penal, no afecta ni contradice ninguno de los objetivos establecidos en el aludido instrumento internacional; todo lo contrario, pues resulta ser una respuesta institucional que logra armonizar dichos propósitos convencionales de protección hacia la mujer con los principios políticos rectores que hacen de base a un sistema de persecución penal igualitario y de mínima intervención ${ }^{31}$.

Sostienen que la obligación de investigar del Estado derivada de la Convención de Belem do Pará constituye una previsión específica que reafirma el mismo deber que la Corte Interamericana ha enunciado a partir del art. 1.1 de la Convención Americana sobre Derechos Humanos, y añaden que si se siguiera el criterio de los defensores de la tesis restrictiva, debería asumirse como consecuencia, por caso, que la suspensión del juicio a prueba tampoco rige para los delitos contra la propiedad, pues también la propiedad privada es objeto de protección de la Convención Americana (art. 21), de manera que frente a un ataque a la propiedad existe el deber del estado de investigar, derivado del art. 1.1. Si ese "deber de investigar" tiene el alcance que sostienen los fallos que critica esta posición, esto es, si exige llegar hasta la sentencia definitiva, todas las legislaciones que prevén sistemas alternativos de resolución de conflictos definidos como delitos, o mecanismos de persecución basados en el principio

31 En tal sentido puede v. BALDIZZONE, Sebastián C., "Suspensión del juicio a prueba. Tesis restrictiva vs. tesis amplia", L.L. 2012-C, 463; LOPARDO, Mauro y ROVATTI, Pablo, "Violencia de género y suspensión del juicio a prueba. Contra los avances de la demagogia punitivista", DJ 11/09/2013, 1 , Cita Online: AR/DOC/1657/2013. 
de oportunidad, deberían considerarse virtualmente derogadas, incluso para delitos tales como el hurto ${ }^{32}$.

En este sentido siguen cierta jurisprudencia que le es conteste, así la correspondiente a la Cámara en lo Penal de Trelew ${ }^{33}$, que resolvió sobre el conflicto normativo entre la Convención de Belém do Pará y el art. 76 bis del CP, estableciendo dicho pronunciamiento, en crítica al precedente "Ortega" de la Cámara Federal de Casación Penal, que “... es conceptualmente errónea e implica una extensión que altera indebidamente el alcance y la finalidad del tratado internacional de protección de los derechos de las mujeres" ${ }^{\prime \prime}$, y se agrega

\begin{abstract}
Es claro que la citada Convención establece que los Estados deben asegurar el acceso de la mujer a la justicia, sin discriminación alguna, en pos de la protección de sus derechos. No caben dudas de la existencia de ese deber estatal indeclinable. Pero una cosa es afirmar esa obligación y otra, distinta, es admitir que dicho marco normativo haya creado un derecho subjetivo de las presuntas víctimas al 'castigo' penal y, mucho menos, que haya derogado en forma implícita derechos consagrados por la ley penal interna, específicamente reglados a favor de toda persona imputada de delitos de leve o mediana gravedad (art. 76 bis CP) (...) convalidar la ampliación de respuestas estatales punitivas -en el caso, a través del mecanismo de restringir el derecho del imputado a obtener la suspensión del juicio a prueba en delitos vinculados a la violencia de género-, no sólo vendría a operar a contramano de las ideas iushumanistas del proceso penal, sino que parecería ir en contra del postulado antidiscriminatorio básico de todo feminismo"35.
\end{abstract}

En el mismo sentido se ha pronunciado la Cámara de Apelaciones Penal, Contravencional y de Faltas de la Ciudad de Buenos Aires ${ }^{36}$.

\footnotetext{
32 LOPARDO y ROVATTI, ob. cit.,

33 Cámara en lo Penal de Trelew, 07/08/2012, en autos "C... S/ denuncia - Trelew" (Carpeta 3.524 OJ Tw - Legajo 31.735 OUMPF Tw)", resolución de fecha 16/10/2012. En el mismo sentido, autos “... S/ dcia... abuso sexual —(Carpeta 3017 OJ Tw — Legajo 26769 OUMPF Tw).

34 Del voto de la juez Rodríguez.

35 Cámara en lo Penal de Trelew, 16/02/2012, carpeta 3.524 OJ Tw, del voto de la juez Rodríguez.

36 Cámara de Apelaciones Penal, Contravencional y de Faltas CABA, 13/03/2012, en autos "Legajo de juicio en autos G., L. S.S/ infr. art. 149 bis CP", s. I., causa n 38178-01-CC/2010,f, del voto de los jueces Marum y Vázquez.
} 


\subsection{El deber de investigar la violencia de género por parte del Estado y negativa de aplicar la suspensión de juicio a prueba a la violencia de género:}

A raíz del dictado del fallo "Góngora", se ha generado una corriente de pensamiento, denominada tesis restrictiva, que considera la improcedencia de la suspensión de juicio a prueba o probation, en casos de violencia de género.

Dicha convicción tiene sustento en lo previsto en el art. 7 inc. " $\mathrm{f}$ " de la Convención Interamericana para Prevenir, Sancionar y Erradicar la Violencia con la Mujer, aprobada por la ley 24.632, conocida como la "Convención de Belem do Pará", que establece:

Los Estados Partes condenan todas las formas de violencia contra la mujer y convienen en adoptar, por todos los medios apropiados y sin dilaciones, políticas orientadas a prevenir, sancionar y erradicar dicha violencia y en llevar a cabo lo siguiente (...) f) establecer procedimientos legales justos y eficaces para la mujer que haya sido sometida a violencia, que incluyan, entre otros, medidas de protección, un juicio oportuno y el acceso efectivo a tales procedimientos.

A partir de dicho pronunciamiento es que un importante sector de la jurisprudencia afirma hoy, con toda generalidad, que la suspensión del proceso a prueba “...es inconciliable con el deber que tiene el Estado de investigar, esclarecer los hechos de violencia contra la mujer, y de sancionar a sus responsables en un juicio con las debidas garantías"37.

Se dice que, como

(...) la suspensión del juicio a prueba obsta a la efectiva dilucidación de hechos que constituirían un delito, ese instituto debe ser considerado en relación con las obligaciones asumidas respecto de la concreta respuesta penal

37 CNCasPenal, Sala II, 30/11/2010, en autos "Calle Aliaga, Marcelo s/ recurso de casación", causa n 13.240, reg. 17.636, voto del juez García. 
frente a sucesos [que impliquen alguna forma de violencia contra la mujer] pues, en estos casos, suspender el juicio a prueba implicaría afectar las obligaciones de prevenir, investigar y sancionar[los]... circunstancia que pondría en crisis el compromiso asumido por el Estado al aprobarla ${ }^{38}$.

En suma, "ni el legislador, ni las autoridades competentes para la persecución penal, gozan de discreción en la decisión acerca de la promoción o continuación de la persecución penal, porque el Estado argentino se ha obligado a prevenir, investigar y sancionar la violencia contra la mujer"39.

Esta posición se ve reforzada más aún en aquellos casos donde el Fiscal, que tiene en su poder el ejercicio de la acción penal, no otorga consentimiento a la probation sea por ser su convicción sea por estar establecido en normas internas de política criminal sobre la persecución penal tal como por ejemplo lo establece el Ministerio Público de la Acusación de la ciudad de Rosario, donde por Resolución No 10/14, "Instructivo general de suspensión de procedimiento a prueba", de fecha 04 de febrero de 2014, en el Anexo I, Punto II - Criterios especiales, se dispone: “(...) 2.- Violencia de género e intrafamiliar: No procede en casos que encuadren dentro de la violencia de género y violencia intrafamiliar. Excepcionalmente, cuando las agresiones hayan cesado por tiempo prolongado y el ofensor no cohabite con la ofendida (...)".

Lo que debe hacerse, según esta tesitura, a la cual adherimos, es hacer un análisis entre la norma internacional invocada y el alcance del art. 76 bis del código de fondo, no debe desatenderse el contexto del artículo en el que ha sido incluido el compromiso del Estado de sancionar esta clase de hechos, siguiendo una interpretación que vincula a los objetivos mencionados con la necesidad de establecer un "procedimiento legal justo y eficaz para la mujer", que incluya "un

38 Del voto del juez Yacobucci en autos "Calle Aliaga", antes citado.

39 CNCasPenal, Sala II, 30/11/2010, en autos "Calle Aliaga, Marcelo s/ recurso de casación”, causa n 13.240, reg. 17.636, voto del juez García. 
juicio oportuno", la norma en cuestión impone considerar que, en el marco de un ordenamiento jurídico que ha incorporado al referido instrumento internacional, tal el caso de nuestro país, la adopción de alternativas distintas a la definición del caso en la instancia del debate oral deviene improcedente ${ }^{40}$.

El impedimento surge de considerar: 1) que el sentido del término juicio expresado en la cláusula $7^{\circ}$ de la Convención resulta congruente con el significado que en los ordenamientos procesales se otorga a la etapa final del procedimiento criminal. Únicamente del juicio oral se puede derivar el pronunciamiento definitivo sobre la culpabilidad o inocencia del imputado, es decir, verificarse la posibilidad de sancionar la clase de hechos exigida por la Convención; y 2) la concesión de la probation al imputado en la causa frustraría la posibilidad de dilucidar en aquél estadio procesal la existencia de hechos que prima facie han sido calificados como de violencia contra la mujer, junto con la determinación de la responsabilidad de quien ha sido imputado de cometerlos y de la sanción que, en su caso, podría corresponderle.

Reiteramos, debe tenerse especialmente en cuenta la oposición a la habilitación de la suspensión del proceso a prueba del Ministerio Público Fiscal. La redacción del art. 76 bis del Código Penal, del que surge, tal como se ha referido, que el dictamen del agente fiscal resulta, en principio, vinculante, sujeto al control jurisdiccional de logicidad y fundamentación, en base a las facultades que posee el mismo en su carácter de titular del ejercicio de la acción pública, en otros términos, la oposición fiscal a la concesión de la probation debe resistir el examen de razonabilidad y legalidad jurisdiccional.

Distinto resulta cuando el titular de la acción penal pública brinda el consentimiento de la probation a situaciones de violencia de género, aquí parte de la jurisprudencia entiende que los magistrados pueden oponerse al otorgamiento de tal instituto, en tanto la suspen-

40 LLERA, Carlos Enrique, "El no de la Corte a la probation en casos de violencia de género", L.L. 2013-E, 449. 
sión del juicio a prueba obsta a la efectiva dilucidación o persecución de hechos que constituirían un delito -impunidad-, la suspensión de juicio a prueba debe ser considerada en relación con las obligaciones asumidas respecto de la concreta respuesta penal frente a sucesos como los que conforman el objeto de requerimiento fiscal. En este sentido la jurisprudencia ha sostenido que

\begin{abstract}
En tal inteligencia, y siendo que la República Argentina aprobó esa Convención a través de la ley 24.632, el consentimiento fiscal para la suspensión del juicio a prueba debe ser ponderado por la instancia jurisdiccional en relación con las obligaciones de prevenir, investigar y sancionar hechos como los aquí considerados, pues estos aspectos hacen al compromiso asumido por el Estado al aprobarla. En ese marco la opinión fiscal favorable a la suspensión del juicio a prueba entra en colisión manifiesta con las obligaciones asumidas por el Estado argentino. En consecuencia, existe un óbice formal de naturaleza legal que impide al Ministerio Público disponer de la persecución penal (...) En tal sentido, el consentimiento brindado por el Ministerio Público ha de ser ponderado concretamente en su legalidad de cara a las exigencias de la Convención de Belen Do Para que trascienden las referencias al modo en que podría cumplirse la supuesta sanción a recaer, la reparación económica y las tareas comunitarias ofrecidas por Ortega o incluso las manifestaciones de la defensa en la audiencia ante esta Sala, calificando el suceso como de bagatela o habitual (...) En virtud de todo ello, el impedimento legal antes aludido quita toda eficacia al consentimiento fiscal y legitima la denegatoria del tribunal ${ }^{41}$.
\end{abstract}

Siguiendo esta tesis, y a los fines de zanjar las posiciones jurisprudenciales y doctrinarias, y consolidar lo establecido por la Corte en el pronunciamiento Góngora, es que se han impulsado proyectos de ley, para reformar el Código Penal, donde se propone impedir la suspensión del juicio a prueba cuando se trate de un delito cometido mediando violencia de género contra las mujeres ${ }^{42}$, según la legisla-

41 CNCasPenal, Sala II, 07/12/2010, en autos “Ortega, René Vicente s/ recurso de casación”, causa n 13.245, reg. 17.700, voto del juez Yacobucci.

42 Dicho proyecto fue aprobado en diciembre de 2014 por la Honorable Cámara de Senadores de la Nación. http://www.parlamentario.com/noticia-78385.html 
dora impulsora de este proyecto - Senadora Sigrid Kunath:

Este proyecto surge de la necesidad de consolidar en la legislación un tema que ya ha sido dictaminado por la Corte Suprema en el caso Góngora que, invocando convenciones internacionales de protección de las mujeres que Argentina ha ratificado, sentó el precedente de no utilizar esta figura procesal en este tipo de casos. Sin embargo, ciertos jueces se han apartado de lo dicho por el máximo tribunal y han concedido este beneficio a imputados en causas penales ${ }^{43}$.

\section{CONCLUSIÓN}

Fue la histórica lucha de las mujeres, ya sea particulares o en grupos, organizaciones nacionales o internacionales, las que nos permitió observar y es dable pensar en la protección de las víctimas de Violencia de Género, actualmente el objetivo primordial de las leyes, en especial la ley 26.485 como su nombre lo indica es: prevenir, sancionar y erradicar la violencia contra las mujeres en los ámbitos en que desarrollen sus relaciones interpersonales. El respeto por la igualdad de género guio los objetivos y propósitos fundamentales tanto del ámbito nacional como el internacional poner en evidencia los abusos que las mismas sufrían por la sola condición de ser tales.

La Convención Interamericana para Prevenir, Sancionar y Erradicar la Violencia contra la Mujer, Convención de Belém do Pará, prevé la obligación de los Estados de adoptar, por todos los medios apropiados y sin dilaciones, políticas orientadas a prevenir, sancionar y erradicar dicha violencia, a lo que se agrega la necesidad de establecer procedimientos legales justos y eficaces para la mujer que haya sido sometida a violencia, que incluyan, entre otros, medidas de protección, un juicio oportuno y el acceso efectivo a tales procedimientos.

Estas obligaciones que ha asumido el Estado argentino provocan fuertes tensiones con otros derechos y garantías constitucionales. Se puede observar que dos cuestiones están generando una fuerte

43 http://www.parlamentario.com/noticia-76552.html 
polémica en los ámbitos jurídicos. Por un lado, la posible relajación de ciertos estándares probatorios para acreditar conductas delictivas teñidas por la violencia de género y por el otro lado, la posibilidad de que un imputado pueda acceder a la probation cuando se le achaca un delito cometido con esa finalidad.

En tal sentido, el consentimiento brindado por el Ministerio Público ha de ser ponderado concretamente en su legalidad de cara a las exigencias de la Convención de Belén do Para que trascienden las referencias al modo en que podría cumplirse la supuesta sanción a recaer, la reparación económica, constituyendo uno de los objetivos el de propugnar el desarrollo de políticas públicas para asistir a las mujeres, prevenir y erradicar este flagelo con penas de efectivo cumplimiento y evitar suspender el juicio a prueba. El respeto por la igualdad de género guió los objetivos y propósitos fundamentales tanto del ámbito nacional como el internacional poniéndose en evidencia los abusos que las mismas sufrían por la sola condición de ser tales, no debiéndose permitir volver a reiterar los mismos, teniendo como norte la sanción a los maltratadores.

\section{INAPPLICABILITY OF PROBATION IN THE CRIMINAL LAW FOR VIOLENCE AGAINST WOMEN}

\section{ABSTRACT:}

Violence against women is present in all societies of the world, constituting one of the most brutal manifestations of gender inequality. Criminal law is a qualified instrument for the protection of particularly important legal rights. With this in mind, it seems necessary to take into account the possibility that their expansion may be due, at least in part, to the emergence of new legal interests - new interests or new pre-existing interests' valuations and to the increase in value experienced by some of those that existed previously, that could legitimize their protection through the Criminal Law. A primary objective to eliminate androcentric 
sociocultural patterns is the incorporation of a gender perspective in the provision of justice, from the field of labor relations to the issuance of resolutions and sentences, through the treatment of victims and the treatment of the causes. The Inter-American Convention to Prevent, Punish, and Eradicate Violence against Women, Belém do Pará Convention, provides for the obligation of States to adopt, by all appropriate means and without delay, policies aimed at preventing, punishing and eradicating such violence, This is compounded by the need to establish fair and effective legal procedures for women who have been subjected to violence, including, inter alia, protective measures, timely adjudication and effective access to such procedures.

Keywords: Violence against women. Criminal law. Probation. The suspension of all or part of a sentence.

\section{REFERÊNCIAS}

AA.VV., "Crítica y Justificación del Derecho Penal en el cambio de siglo", coords.: Luis Arroyo Zapatero y otros, (Cuenca, Ediciones de la Universidad de Castilla-La Mancha, 2003).

BACLINI, Jorge C., "Código Procesal Penal de la Provincia de Santa Fe. Ley No 12.734", Tomo I - arts. 1 a 125-, (Rosario, Juris, 2010), pág. 133.

BALDIZZONE, Sebastián C., "Suspensión del juicio a prueba. Tesis restrictiva vs. tesis amplia", L.L. 2012-C, 463; LOPARDO, Mauro y ROVATTI, Pablo, "Violencia de género y suspensión del juicio a prueba. Contra los avances de la demagogia punitivista", DJ 11/09/2013, 1, Cita Online: AR/DOC/1657/2013. Cámara de Apelaciones Penal, Contravencional y de Faltas CABA, 13/03/2012, en autos "Legajo de juicio en autos G., L. S.S/ infr. art. 149 bis CP", s. I., causa n³8178-01-CC/2010,f, del voto de los jueces Marum y Vázquez.

CNCasPenal, Sala II, 07/12/2010, en autos "Ortega, René Vicente s/ recurso de casación", causa n 13.245, reg. 17.700, voto del juez Yacobucci.

CNCasPenal, Sala II, 30/11/2010, en autos "Calle Aliaga, Marcelo s/ recurso de casación", causa n¹3.240, reg. 17.636, voto del juez García.

DE OLAZABAL, Julio, "Suspensión del proceso a prueba", (Buenos Aires, 
Astrea, 1994), págs. 19/20.

ERBETTA, Daniel, FRANCESCHETTI, Gustavo y ORSO, Tomás, 'Código Procesal Penal de la Provincia de Santa Fe. Texto vigente según leyes 6740, 12734 y 12912, Análisis y comentario a la Ley de implementación Progresiva y artículos de la ley 12734 que entran en vigencia', (Santa Fe, Rubinzal Culzoni, 2009), pág. 120.

FACIO, Alda, 'Con los lentes del género se ve otra justicia', en AA.VV., 'Otras miradas de la justicia. El otro derecho', número 28, “Bogotá, ILSA -Instituto Latinoamericano de Servicios Legales Alternativos, 2002), págs. 95/6.

FREELAND LOPEZ LECUBE, Alejandro y TAMINI, Adolfo, “¿Probation a la manera americana, a la europea o qué?", J.A. 1994-IV, 859.

HASSEMER, Winfried, "Persona, mundo y responsabilidad", trad. de Francisco Muñoz Conde y María del Mar Díaz Pita, (Colombia, Temis, 1999), págs. 15 y ss. Honorable Cámara de Diputados de la Provincia de Buenos Aires, Diccionario de Género. Incluye la Ley Provincial 12.569, http://www.hcdiputados-ba.gov. ar/weboaci/files/diccionario.pdf (consultada el 08/01/2015)

IRIBARREN, Pablo E., "Violencia de género y suspensión de juicio a prueba", DJ 24/12/2014, 21, Cita Online: AR/DOC/3677/2014.

JESCHECK, Hans - Heinrich, "Tratado de Derecho Penal, Parte General", $4^{\circ}$ Edición, Traducción de José Luis Manzanares Samaniego, (Granada, España, Editorial Comares - Granada, 1993), pág. 1.

LLERA, Carlos Enrique, "El no de la Corte a la probation en casos de violencia de género", L.L. 2013-E, 449.

LUZON PEÑA, Diego Manuel, "Curso de Derecho Penal, Parte general”, tomo I, $1^{\circ}$ edición, $1^{\circ}$ reimpresión, (Madrid, Editorial Universitas S.A., 1999), pág. 79. MEDINA, Juan J., "Violencia contra la mujer en la pareja”, (Valencia, Tirant lo Blanch, 2002), pág. 377.

RODRIGO, Fernando M., “Estrategias de defensas para mujeres que responden a las agresiones de sus maltratadores", en Sup. Penal2013 (septiembre), 3 - L.L. 2013-E, 544.

SILVA SANCHEZ, Jesús María, "La expansión del Derecho Penal", $2^{\circ}$ edición, (Madrid, Civitas, 2001), págs. 25 y VITALE, Gustavo L., "Estado constitucional de Derecho y Derecho Penal", en AA.VV., "Teorías actuales en el Derecho Penal", (Buenos Aires, Ad-Hoc, 1998), págs. 74/5. 